\title{
PERFORMANCE INVESTIGATION OF A VOLUTE POROUS TONGUE OF A TURBOCHARGER TURBINE
}

\author{
Abderrahmane Chachoua ${ }^{*}$ - Mohamed Kamal Hamidou' ${ }^{1}$ Mohammed Hamel $^{1}$ \\ ${ }^{1}$ Department of mechanical engineering, Faculty of mechanical engineering, University of Sciences and Technologies \\ Mohamed Boudiaf of Oran, El Mnaouar, BP 1505, Bir El Djir 31000, Algeria
}

\begin{tabular}{l}
\hline ARTICLE INFO \\
\hline Article history: \\
Received: 26.12 .2017$. \\
Received in revised form: 23.6 .2018$. \\
Accepted : 1.8 .2018$. \\
\hline Keywords: \\
Volute \\
Scroll \\
Tongue \\
Mixed inflow turbine \\
ANSYS-CFX \\
\hline DOI: http://doi.org/10.30765/er.40.1.08
\end{tabular}

\section{Introduction}

Realizing the growing importance and availability of motor vehicles, turbochargers became widely spread in diesel engine applications, for improving fuel

\begin{abstract}
:
The design for better performance of the spiral housing volute used commonly in radial and mixed inflow gas turbines is of prime importance as it affects the machine stage at both design and off design conditions. The tongue of the scroll divides the flow into two streams, and represents a severe source of disturbances, in terms of thermodynamic parameter uniformity, maximum kinetic energy, the right angle of attack to the rotor and minimum losses. Besides, the volute suffers an undesirable effect due to the recirculating mass flow rate in near bottom vicinity of the tongue. The present project is an attempt to design a tongue fitted with cylindrical holes traversing normal to the stream wise direction, where on account of the large pressure difference between the top and the bottom sides of the tongue will force the recirculating flow to go through the rotor inlet. This possibility with its limitations has not yet been explored. A numerical simulation is performed which might provide our suitable objectives.

To achieve this goal the ANSYS code is used to build the geometry, generate the mesh, and to simulate the flow by solving numerically the averaged Navier Stokes equations.

Apparently, the numerical results show evidence of favorable impact in using porous tongue. The realization of a contact between the main and recirculation flow by drilled holes on the tongue surface leads to a flow field uniformity, a reduction in the magnitude of the loss coefficient, and a $20 \%$ reduction in the recirculating mass flow rate.
\end{abstract}

consumption and reducing $\mathrm{CO}$ emissions. The mixed inflow turbine is suitable for systems where compact power sources are required with higher boost pressure. The volute has to feed the full azimuth of the turbine, it also imparts significant swirl to the gas achieving the most favorable flow conditions at the

\footnotetext{
${ }^{*}$ Corresponding author. Tel: +213561324677

E-mail address: chachoua.a@yahoo.com
} 
rotor entrance. The inlet scroll plays a very significant task, in the available energy transformation; great attention must be directed to it. A volute with a porous tongue is tested to achieve the suitable objectives and it is compared with the original scroll (without holes) designed and tested at the University of Imperial College of London. The purpose of this work has nothing to do with the suction of the boundary layer or the film cooling technics M.K Hamidou and al. [1]. So we take advantage of the expansion process through the converging spiral housing (volute) of the turbine from its subsonic inlet at zero azimuth angle located on the tongue to the lowest pressure at the volute exit located beneath the tongue in the vicinity of $355^{\circ}$ azimuth angle, resulting in a strong pressure gradient between the upside and the downside of the tongue. By analogy with airfoils, the aerodynamic profile shape induces a pressure gradient; in our case we already possess a large pressure difference due to the expansion process. From observations and references, it happens that the gas beneath the tongue does not have sufficient energy to continue its expansion through the turbine rotor. This amount of gas stagnates in this area and it is called therecirculating mass flow rate, which causes severe losses. M Abidat et al. [2], observed the complex flow structure downstream of the volute tongue that affects in a direct manner the flow distribution at the inlet of the rotor. K.Miyanaga et al. [3] concluded that the design of the leading edge of the tongue has a significant impact on volute performance at high flow rates. H. Chen. [4], found that the main tongue effect is that it generates a wake at the meeting of the two streams at the trailing edge with different speeds. K.R PULLEN [5] in their experimental study of a radial turbine with a high pressure ratio found that the flow is transformed from a uniform flow at the inlet of volute casing to vortex flow at a distance of $15^{\circ}$ downstream tongue.

SA Mac Gregor et al. [6] according to their experimental investigations of studying the structure of the flow in a radial turbine scroll, they deduced that the increase in the radial velocity observed for several azimuth angle values is due to the influence tongue which causes the flow turned to the rotor at this point. Fredrik Hellstrom et al. [7] in his study evaluates the effect of inlet conditions on the performance of a radial turbine of a turbocharger using the turbulence model LES. This showed that the wake created downstream of tongue causes a large speed fluctuation in the wheel.
A symmetric azimuthal volute section is used, this volute is developed from another asymmetrical dimension of a mixed flow turbine designed and reviewed by Abidat [8] and Abidat and others [9]. The conditions of numerical tests are taken fromthe experimental data of Chen and others [10].

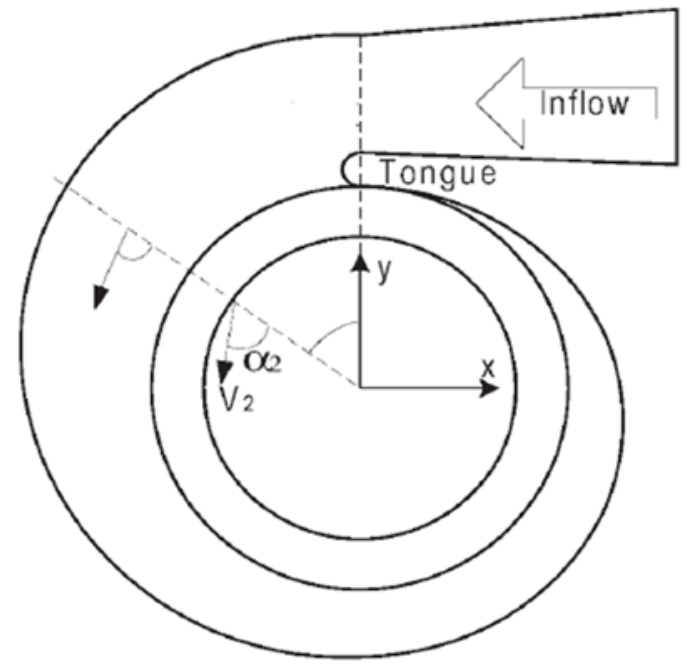

Figure 1. Schematic view of the scroll

- $\quad$ Spiral housing Inlet section

$A_{0}=1.702 \times 10^{-3} \mathrm{~m}^{2}$

- $\quad$ Radius gravity center of the inlet section $r_{0}=80.53 \times 10^{-3} \mathrm{~m}$.

- $\quad$ Mean radius at the outlet of the volute $r_{2}=41.79 \times 10^{-3} \mathrm{~m}$.

\section{Flow simulation in the volute}

The highly three dimensional, viscous, and compressible flow field in the volute is investigated by solving numerically the Reynolds average conservation equations of mass, momentum, and energy. The turbulence is modeled by the standard k$\varepsilon$ model, based on the eddy viscosity concept which assumes that the Reynolds stresses $-\rho \overline{u_{\imath} u_{\jmath}}$ can be expressed in terms of the mean velocity gradient and the eddy turbulent viscosity $\mu_{\mathrm{t}}$.

\section{The governing equations}

\subsection{Mass conservation equation}

$$
\frac{\partial \rho}{\partial t}+\nabla \bullet(\rho \vec{U})=0
$$




\subsection{Momentum conservation equations}

$$
\frac{\partial(\rho \vec{U})}{\partial t}+\nabla \bullet(\rho \vec{U} \otimes \vec{U})=\nabla(-p \delta+\tau-\rho \overrightarrow{\vec{u} \otimes \vec{u}})+S_{M}
$$

The Coriolis and centrifugal forces are included in the source term.

\subsection{Energy conservation equation.}

$$
\frac{\partial(\rho H)}{\partial t}+\nabla \bullet(\rho \vec{U} H-\rho \overline{\vec{u} h}-\lambda \nabla T)=\frac{\partial P}{\partial t}
$$

$\mathrm{H}$ is mean total enthalpy given by:

$$
H=h_{s}+\frac{1}{2} \vec{U}^{2}+k
$$

The additional term $k$ in the total energy equation is the turbulent kinetic energy defined as follows:

$$
k=\frac{1}{2} \vec{u}^{2}
$$

Static temperature, static pressure $P$ and density $\rho$ are related by the equation of state:

$$
P=\rho R T
$$

The k- $\varepsilon$ model assumes that the eddy viscosity $\mu_{t}$ is linked to the turbulent kinetic energy $k$ and its dissipation rate $\varepsilon$ through the following relation:

$$
\mu_{t}=\rho C_{\mu} \frac{k^{2}}{\varepsilon}
$$

Where $C_{\mu}=0.09, k$ and $\varepsilon$ are defined through the following two equations:

$$
\begin{gathered}
\frac{\partial(\rho k)}{\partial t}+\nabla \bullet(\rho k \vec{U})=\nabla \bullet\left[\left(\mu+\frac{\mu_{t}}{\sigma_{k}}\right) \nabla k\right]+ \\
P_{k}-\rho \varepsilon \\
\frac{\partial(\rho \varepsilon)}{\partial t}+\nabla \bullet(\rho \overrightarrow{\varepsilon U})=\nabla \bullet\left[\left(\mu+\frac{\mu_{t}}{\sigma_{\varepsilon}}\right) \nabla \varepsilon\right] \\
+\frac{\varepsilon}{K}\left(C_{1 \varepsilon} P_{K}-C_{2 \varepsilon} \rho \varepsilon\right)
\end{gathered}
$$

In this model, $\mathrm{P}_{k}$ is the turbulence production and the following constants are determined experimentally from a wide range of turbulent flows (Patankar and Spalding) [11] $\sigma_{k}=1.00$,

$$
\sigma_{\varepsilon}=1.30, C_{1 \varepsilon}=1.44, C_{2 \varepsilon}=1.92 .
$$

\section{Methodology}

For the purpose of relating the main flow at the volute entrance to the re-circulating flow at the end spiral path of the scroll, cylindrical channels are drilled on the surface of the tongue. The effectiveness of the method is noticed for holes diameters greater than 4 $\mathrm{mm}$ as shown in Fig 2.

The optimal number of rows is investigated having in mind the practical limit of the tongue length, according to the tendency of the flow to separate. Eventually a fair compromise solution can be found when the tongue is suitably shaped, properly oriented in the flow for a better guidance and provided with an optimal number of holes.

Four configurations will be studied and compared (Fig. 2).

1. Tongue without orifices.

2. Tongue with one row of three orifices.

3 . Tongue with two rows of three orifices.

4. Tongue with three rows of three orifices.

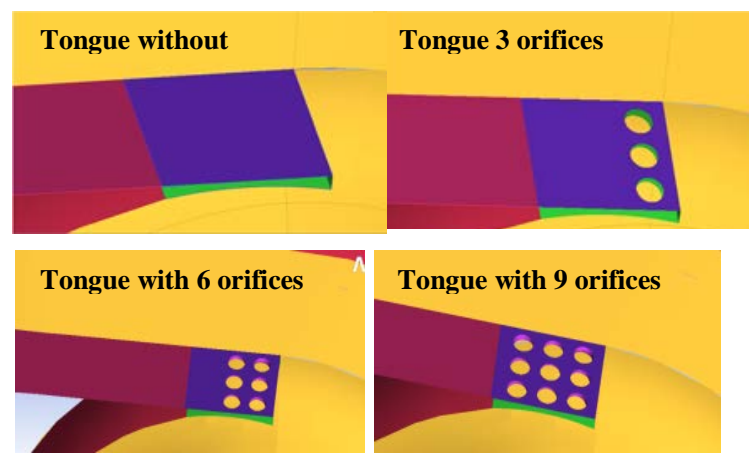

Figure 2. Different configurations of the tongues

\section{Definition of computational domain}

For all simulations, the computational domain is defined using the CFX-Pre module. The fluid is a perfect gas. The flow regime is steady. The adopted model of turbulence is $\mathrm{k}-\varepsilon$. The boundary conditions are defined as follows:

At the inlet, the flow regime is subsonic, the total pressure and temperature are imposed. At the outlet, the flow regime is subsonic and the mass flow rate is imposed. The walls are smooth, fixed and adiabatic. The approach method used to solve the averaged equations is the finite volume method, a high precision distribution scheme is chosen and an 
average end iteration residue of $10^{-5}$ is adopted, the maximum number of iterations is fixed at 100 .

The numerical simulations performed for all configurations use experimental data, introducing a total temperature of $333.82 \mathrm{~K}^{\circ}$, a total pressure of 1.445 bar; both at the volute inlet and a mass flow rate of $0.292 \mathrm{Kg} / \mathrm{s}$. For safety reasons and rig equipment coasts, temperatures and rotational speeds at which tests are conducted, are much lower than those encounter in real applications.

\section{Grid solution dependency}

The mesh generation should be carefully treated, and it deserves a special attention in order to discard any dependency on the flow field solutions in the resolution of the three-dimensional, compressible, viscous flow. A refined grid generation is recommended in flow regions with high gradients (Fig. 3). The optimal cell number test is performed on the different tongue configurations, adopting the static pressure distribution along the mean streamline which starts from the volute inlet. The solutions obtained with the four grids are presented in Fig. 4. After consulting the results, the numbers of cells listed in table 1 were found to give a satisfactory solution and were used for the numerical tests.

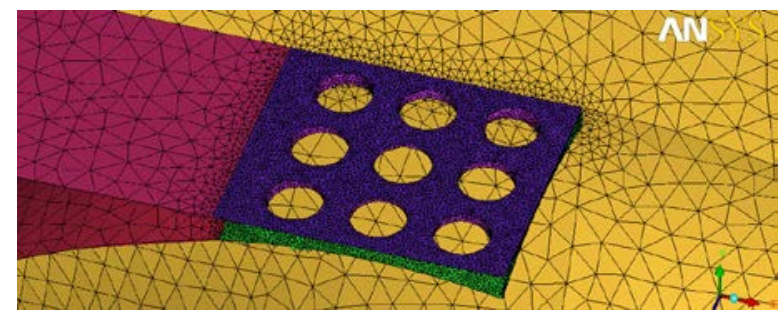

Figure 3. Mesh refinement in tongue region

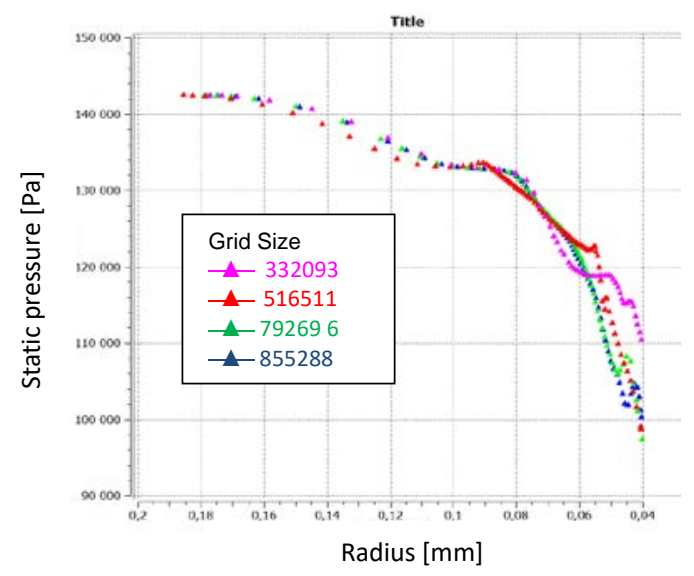

Figure 4. Grid solution independency
Table 1. Number of elements for different configurations

\begin{tabular}{|c|c|c|c|c|}
\hline $\begin{array}{c}\text { Tongue } \\
\text { types }\end{array}$ & $\begin{array}{c}\text { Without } \\
\text { orifices }\end{array}$ & $\begin{array}{c}\text { One } \\
\text { row of 3 } \\
\text { orifices }\end{array}$ & $\begin{array}{c}\text { Two } \\
\text { rows of 3 3 } \\
\text { orifices }\end{array}$ & $\begin{array}{c}\text { Three } \\
\text { rows of 3 } \\
\text { orifices }\end{array}$ \\
\hline size & 792696 & 892972 & 855228 & 844217 \\
\hline
\end{tabular}

\section{The results and discussion}

The results of the flow field numerical prediction such as the Mach number, the pressure, the absolute flow angle, the loss coefficient and recirculating mass flow rate are presented and compared to the original tongue; without holes, tongue with a row of three holes, with a rows of six holes and with a rows of nine holes, as shown in Fig. 2.

\subsection{Flow field parameters along the mean stream line}

In order to ascertain that a converging channel accelerates a subsonic flow, the parameters under consideration are given along the mean stream line (see Fig. 5).

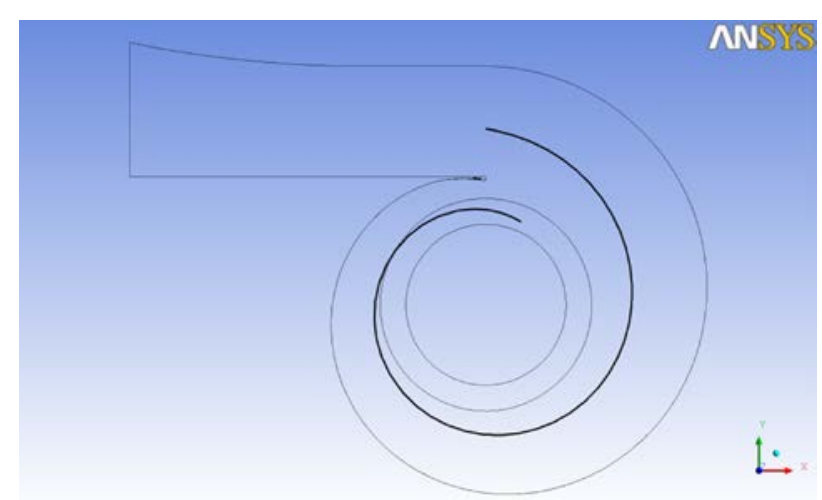

Figure 5. Average streamline flow path

If we consider the tongue as an aerodynamic airfoil, the use of the orifices will reduce the pressure difference between the surface sides: - on the tongue and on the reverse side of the tongue. In the vicinity of the tongue reverse side, we observe an increase in pressure with the number of orifices (Fig. 6), and obviously a fall in the magnitude of the Mach number (Fig. 7). 


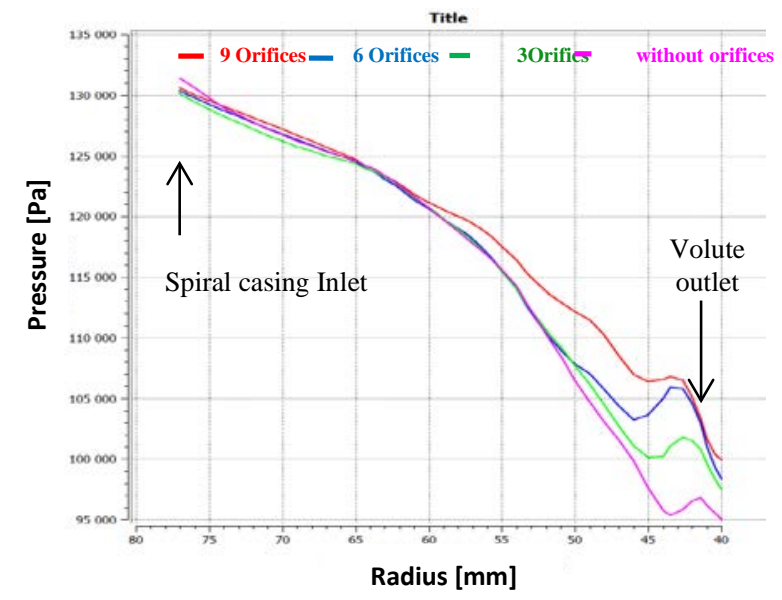

Figure 6. Variation of the static pressure along the average stream line according to the radial position $\left(\mathrm{P}^{*}=1,445\right.$ bar $)$

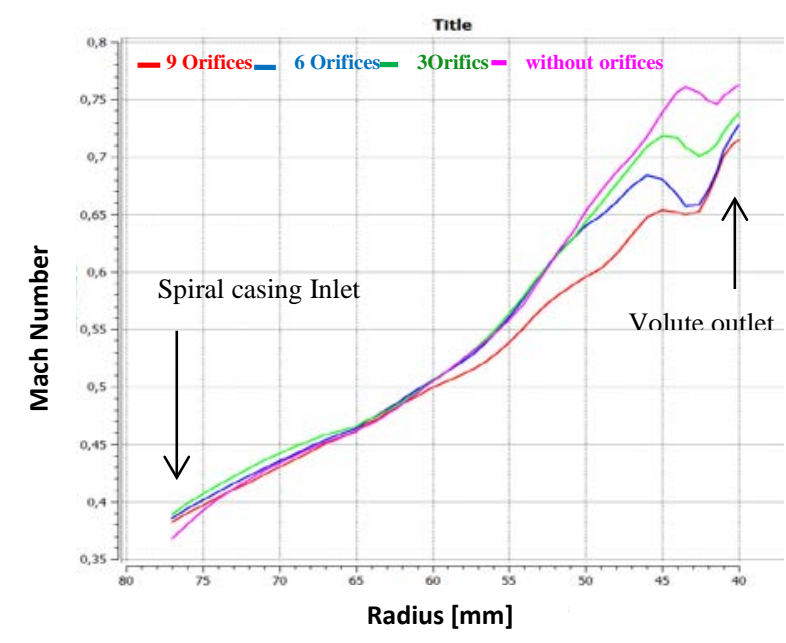

Figure 7. Variation of the Mach number along the average stream line according to the radial position $\left(\mathrm{PO}^{*}=1.445\right.$ bar $)$

The effect of the orifices on the flow field is remarked when we approach the tongue. The loss coefficient presented in Fig. 8 diminishes with the use of a larger number of orifices, the non-uniform change in radial velocity (Fig. 9), influences the distribution of the flow angle (Fig. 10).

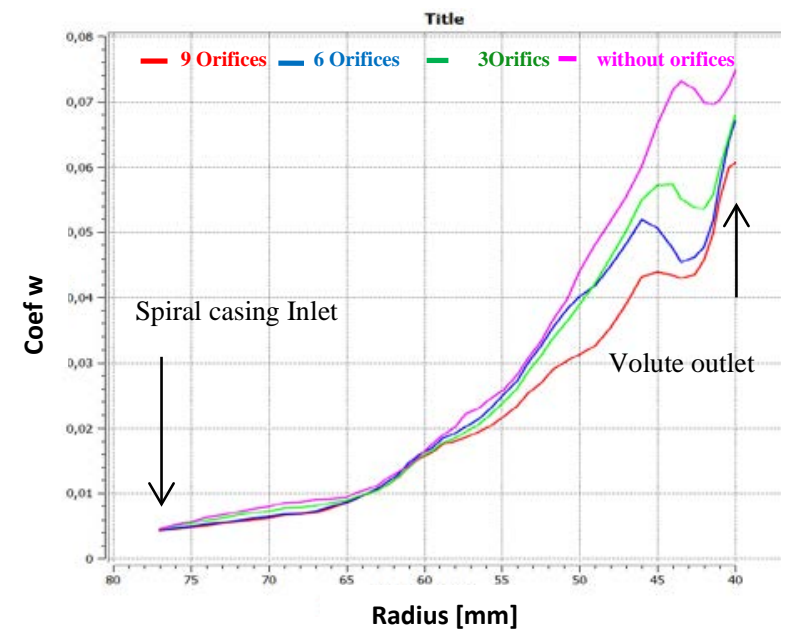

Figure 8. Variation of the total pressure loss coefficient along the average stream line according to the radial position $\left(\mathrm{PO}^{*}=\right.$ 1.445 bar)

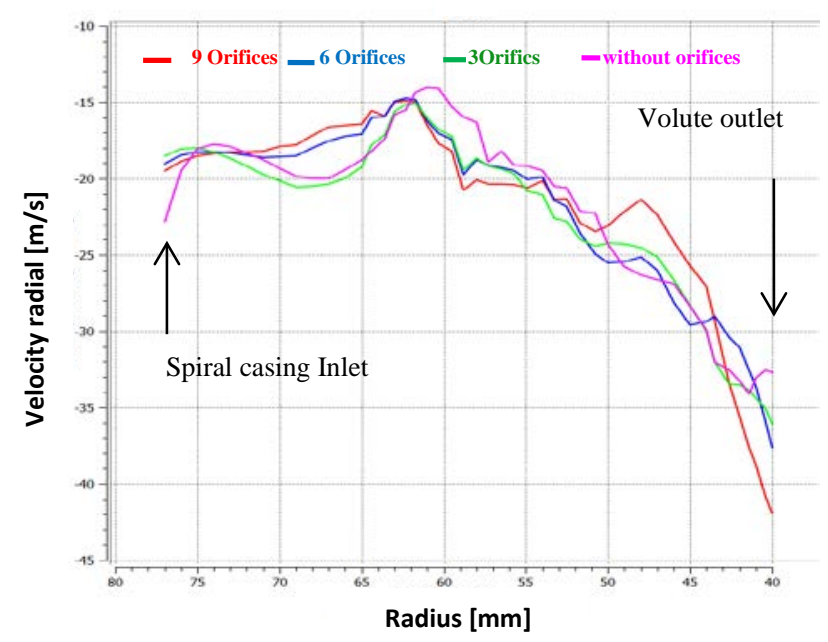

Figure 9. Variation of the radial velocity along the average stream line according to the radial position $\left(\mathrm{P} 0^{*}=1,445\right.$ bar $)$ 


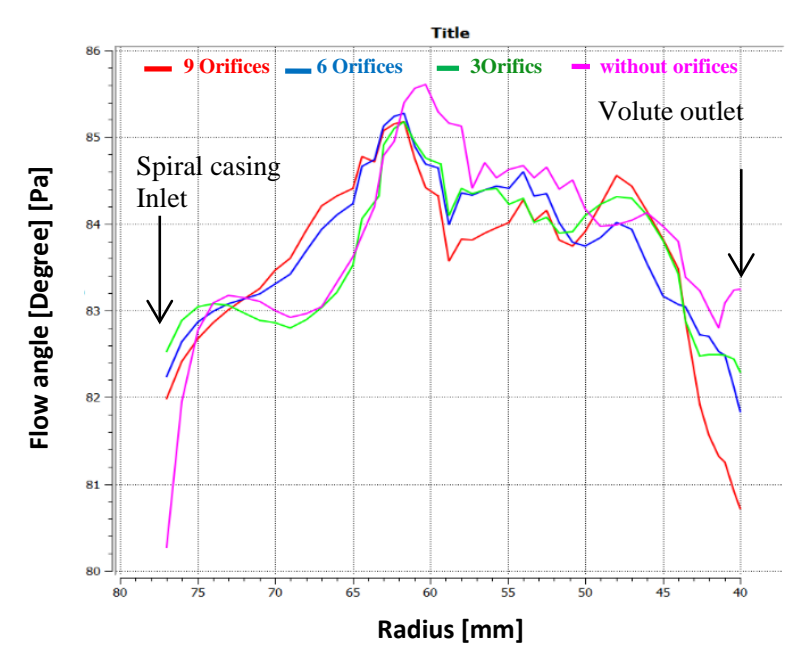

Figure 10. Variation of the Flow angle along the average stream line according to the radial position $\left(\mathrm{PO}^{*}=1,445\right.$ bar $)$

\subsection{Flow field parameters around the rotor entrance}

We are aware that the tongue perturbation on the flow fields is significant and that it induced a degradation of the volute performances. The use of orifices on the tongue surface seems to introduce like a damping effect of the tongue disturbance leading to a more uniform flow field distribution with increased number of orifices see Figs. (12, 13, 14, and 15).

In addition, the loss coefficient is reduced (Fig. 15). The effect of the tongue is strongly remarkable on the reverse side where a recirculating mass flow rate exists. It is apparent from the results of this investigation that the effect of cylindrical holes drilled on the tongue surface reveals some interesting benefits with regard to the performance of the volute.

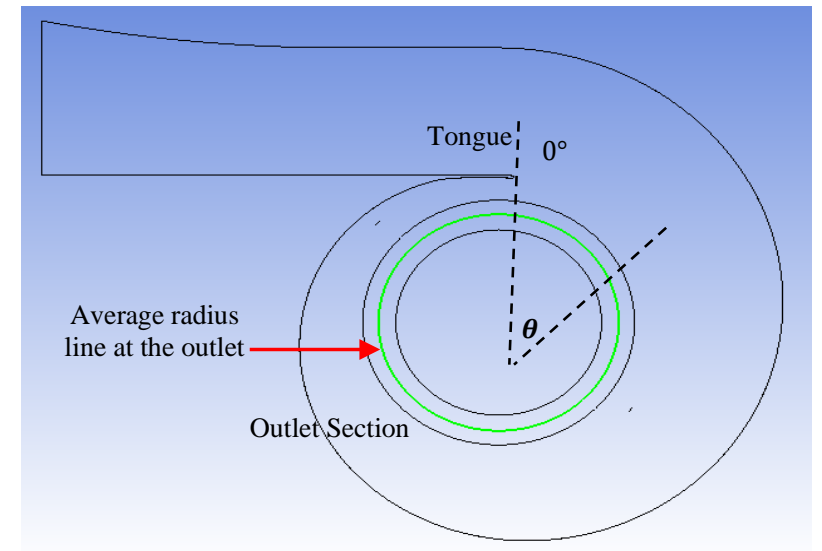

Figure 11. The average radius line at the outlet of the volute

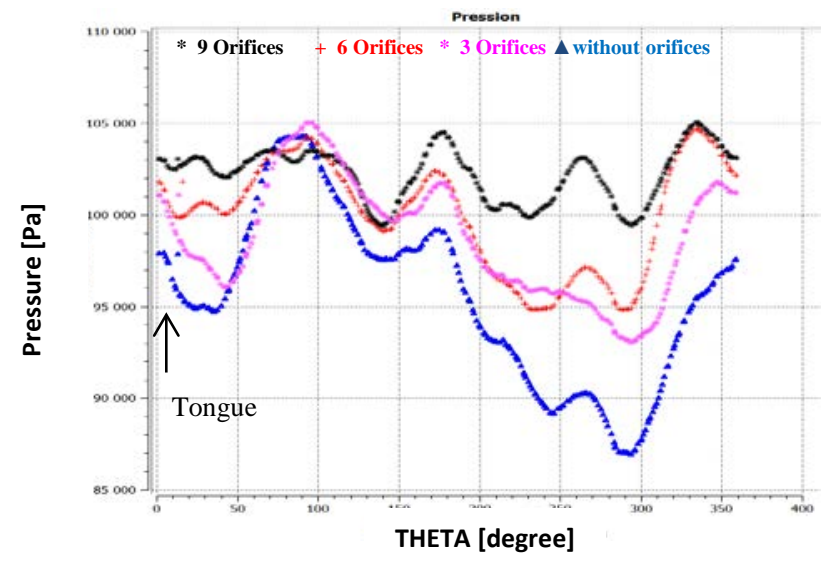

Figure 12. Variation in the Pressure as a function of the azimuth angle in the mean radius line around the rotor entrance $\left(P 0^{*}=\right.$ 1.445 bar)

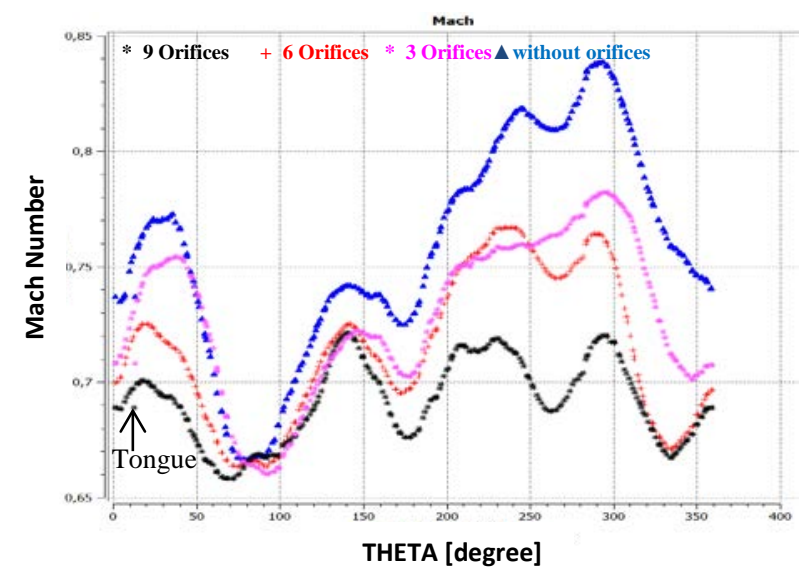

Figure 13. Variation in the number of Mach as a function of the azimuth angle in the mean radius line around the rotor entrance $\left(\mathrm{PO}^{*}=1.445\right.$ bar $)$. 


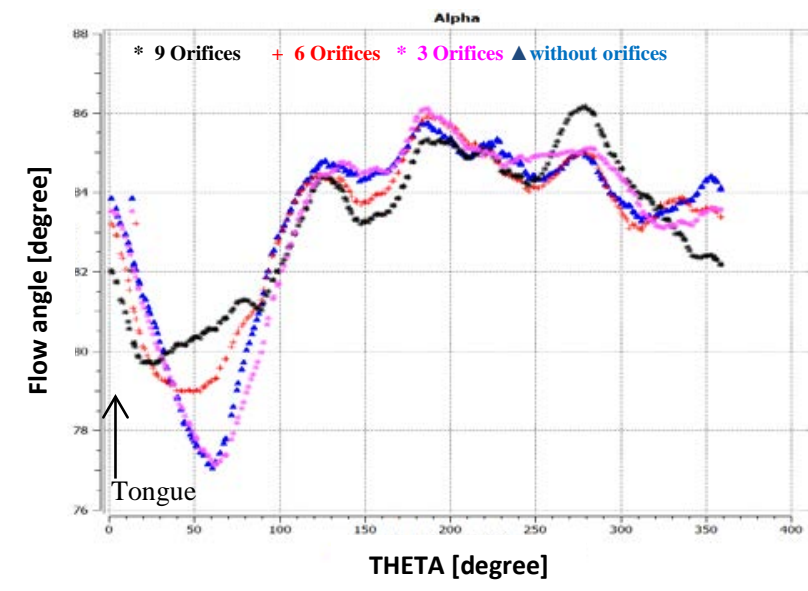

Figure. 14: Variation of flow angle as a function of the azimuthal angle in the mean radius line around the rotor entrance $\left(\mathrm{P} 0^{*}=\right.$ 1,445 bar)

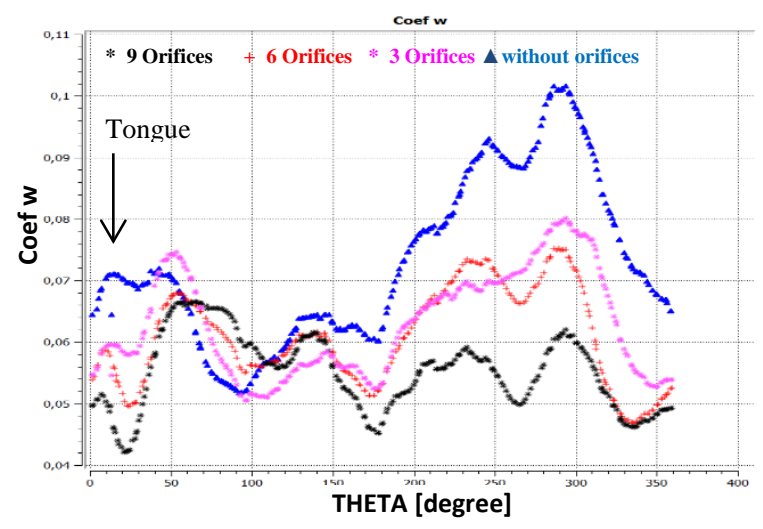

Figure 15. Variation of the total pressure loss coefficient as a function of the azimuth angle in the mean radius line around the rotor entrance $\left(\mathrm{P} 0^{*}=1.445\right.$ bar $)$

\subsection{Recirculating mass flow rate estimation}

In order to quantify the recirculating mass flow rate, we choose a cross section just beneath the tongue; on its reverse side; to calculate the mass flow rate. The obtained values are given in the following table for different number of orifices.

We have effectively retained a decrease in the recirculating mass flow rate as we increase the number of orifices; we have reached $20 \%$ decrease in the recirculating mass flow rate with 09 orifices. The analysis shows favorable results.
Table 2. Recirculating mass flow rate

\begin{tabular}{|c|c|c|c|}
\hline $\begin{array}{c}\text { Recircula- } \\
\text { ting mass } \\
\text { flow rate } \\
\text { without }\end{array}$ & $\begin{array}{c}\text { Recircula- } \\
\text { ting mass } \\
\text { flow rate } \\
\text { with 3 } \\
\text { orifices }\end{array}$ & $\begin{array}{c}\text { Recircula- } \\
\text { ting mass } \\
\text { flow rate } \\
\text { with } 6\end{array}$ & $\begin{array}{c}\text { Recircula- } \\
\text { ting mass } \\
\text { flow rate } \\
\text { with } 9 \\
\text { orifices }\end{array}$ \\
\hline $10 \mathrm{~g} / \mathrm{s}$ & $9.3 \mathrm{~g} / \mathrm{s}$ & $8.45 \mathrm{~g} / \mathrm{s}$ & $8 \mathrm{~g} / \mathrm{s}$ \\
\hline
\end{tabular}

\section{Conclusion}

The objective of this study is to give the designer an appreciation of certain flow parameter features linked with the use of porous tongue. This possibility with its limitations has not yet been explored. We realized the contact between the main and the recirculating flow through rows of holes drilled on the surface of the tongue. Thus, the gas can be sucked away due to the large pressure difference between the side on and the reverse side of the tongue. A compromise is required, between having more rows of holes; this causes a better effectiveness but we need longer tongue in the flow direction, which has incurred performance penalty. We retain from this analysis, the inherent benefits in using a porous tongue; such as a uniform flow, a decrease in the strength of the wake downstream of the tongue, reduced losses and diminishing recirculating mass flow rate about $20 \%$. It is encouraging to note that the estimated trends agree reasonably with the essence of the design.

\section{Nomenclature}

$$
\begin{aligned}
& \mathrm{H}=\text { mean total enthalpy } \\
& \mathrm{h}_{\mathrm{s}}=\text { mean static enthalpy } \\
& k=\text { turbulent kinetic } \\
& p=\text { pressure } \\
& \mathrm{R}=\text { air gas constant } \\
& \mathrm{S}_{\mathrm{M}}=\text { source term } \\
& \mathrm{T}=\text { mean static temperature } \\
& \overrightarrow{\mathrm{U}}=\text { mean velocity vector. } \\
& \mathrm{V}_{2}=\text { outlet absolute speed. } \\
& \vec{u}=\text { fluctuating velocity vector } \\
& \rho=\text { density } \\
& \mu_{e f f}=\text { effective viscosity } \\
& \delta=\text { Kronecker delta function } \\
& \tau=\text { molecular stress tensor } \\
& \lambda=\text { thermal conductivity } \\
& \mu_{t}=\text { turbulent viscosity } \\
& \varepsilon=\text { energy dissipation rate } \\
& \alpha_{2}=\text { outlet flow angle }
\end{aligned}
$$




\section{References}

[1] Guelailia, A., Khorsi, A., Hamidou, M. K.: Computation of leading edge film cooling from a console geometry (converging slot hole), Thermophysics and Aeromechanics, 23 (2016), 1, 33-42.

[2] Abidat, M., Hamidou, M. K., Hachemi, M., Hamel, M.: Design and flow analysis of radial and mixed flow turbine volutes, European Conference on Computational Fluid Dynamics ECCOMAS CFD, the Netherlands, 2006.

[3] Miyanaga, K., Kobayashi, T., Ichimiya,T., Sakai, T., Whitfield, A.: A study of volute tongue and passage design on the performance of centrifugal Turbomachines, 14th Australasian Fluid Mechanics Conference, Adelaide University Adelaide, Australia, 2001, 493-496.

[4] Chen, H.: Design methods of volute casings for turbocharger turbine applications, Proceedings of the Institution of Mechanical Engineers, Part A : Journal of Power and Energy, 210 (1996), 2, 149-156.

[5] Pullen, K. R., Baines, N. C., Hill, S. H.: The design and evaluation of a high pressure ratio radial turbine, ASME,International Gas Turbine and Aeroengine Congress and Exposition, Cologne Germany,1992,V001T01A050.

[6] MacGregor, S. A., Whitfield, A., Mohd Noor, A. B.: Design and performance of vaneless volutes for radial inflow turbines, Part 3: experimental investigation of the internal flow structure, Proceedings of the Institution of Mechanical Engineers, Part A : Journal of Power and Energy, 208 (1994), 4, 295-302.

[7] Hellstrom, F., Fuchs, L.: Effects of inlet conditions on the turbine performance of $a$ radial turbine, ASME, Turbo Expo 2008: Power for Land, Sea and Air, Berlin, Germany, 2008, GT2008-51088.

[8] Abidat, M.: Design and testing of a Highly Loaded Mixed Flow Turbine, PhD Thesis, Imperial College, London, 1991.

[9] Abidat, M., Chen, H., Baines, N.C., Firth, M.R.: Design of a Highly Loaded Mixed Flow Turbine, Proceedings of the Institution of Mechanical Engineers, Part A: Journal of Power and Energy, 206 (1992), 2, 95-107.

[10] Abidat, M., Hamel, M., Litim, S. A., Hamidou, M. K., Hachemi, M.: Prevision performances and design optimization of a mixed flow turbine, 18th French Congress of mechanics, Grenoble France, 2007.
[11] Patankar, S. V., Spalding, D. B.: A calculation procedure for heat, mass and momentum transfer in three-dimensional parabolic flows, International journal of heat and mass transfer, 15 (1972), 10, 1778-1806. 